\title{
THE INVESTIGATION OF A LARGE FAMILY AFFECTED WITH VON WILLEBRAND'S DISEASE
}

\author{
BY \\ J. C. W. MACFARLANE and M. J. SIMPKISS \\ From The Hospital for Sick Children, Great Ormond Street, London
}

(RECEIVED FOR PUBLICATION JUNE 9, 1954)

Originally in 1926 and later in 1931 and 1933 von Willebrand and his colleagues published details of a family with a hereditary haemorrhagic diathesis which has since become established as the clinical syndrome known as von Willebrand's disease (von Willebrand, 1926, 1931; von Willebrand and Jürgens, 1933; Jürgens and Naumann, 1931). Of the 66 members in this family, 22 were affected. The dyscrasia was characterized by a tendency to bleed, especially in the form of recurrent epistaxis and intractable haemorrhage following dental extractions, accompanied by a normal coagulation time, no reduction in the number of platelets, a prolonged bleeding time, and, in the one case so investigated, efficient clot retraction. In this particular family both sexes were affected, the disease being inherited as a Mendelian dominant, but while the disease in females appeared to be either severe or mild in degree, the males were all affected to the same moderate degree. von Willebrand and his colleagues sought to prove that in this condition the platelets were qualitatively deficient. This theory led von Willebrand and his colleagues, and later other authors reporting further similar families, to regard this dyscrasia as being an example of 'thromboasthenia' akin to the condition described by Glanzmann (1918), in which the bleeding tendency was characterized by deficient clot retraction and abnormal platelet morphology.

In 1941 Macfarlane described five cases resembling those of von Willebrand. He demonstrated that there was no platelet abnormality and that clot retraction was normal, but that the capillaries of the nail folds were abnormal in shape and failed to contract after puncture. He suggested that the abnormality was caused by an inherited capillary defect and not by a platelet functional deficiency, pointing out that in the literature of similar cases the clot retraction had usually been reported as normal.

Estren, Sanchez Médal and Dameshek (1946) reviewed 62 cases from the literature and added 11 of their own which they had investigated, adding weight and detail to the clinical picture of the condition but confusion to its aetiology by reverting to von Willebrand's original name of 'pseudohaemophilia', for, as is pointed out by Biggs and Macfarlane (1953) in their review of the literature, this haemorrhagic diathesis 'bears no genetic, clinical or pathological resemblance to true haemophilia'.

Gradually the clinical features of the syndrome and the haematological findings in it have become clarified until a definite disease entity is now established. Perkins (1946) reported a family of 37 members in which six males were affected in five generations, confirming the general pattern of the condition and adding that it appeared to be cyclic and tended to become less severe with increasing age. The same capillary abnormality noted by Macfarlane was observed, and in this family the disease appeared to be sex-linked. Levy (1947) investigated a family of 62 members extending over four generations and containing 20 affected persons, 12 females and eight males. The onset of the abnormality varied from 4 months to 4 years, and again it appeared to be cyclic and to diminish in severity with the years. One affected member suffered from haematuria for which only the dyscrasia could be found as the cause, and two-thirds of the affected females suffered from menorrhagia and postpartum haemorrhages. Five members had died of haemorrhage - three intrapulmonary, one following a gun-shot wound, and one of uterine origin. Once more the capillary abnormality was reported. These symptoms were again in addition to the accepted pattern of recurrent epistaxis, easy bruising, intractable bleeding following dental extractions, haemorrhage from the gastro-intestinal tract, occasional joint involvement, and the hazard of surgical interference. Revol, Favre-Gilly and Ollagnier (1950) critically reviewed 91 published cases, agreeing that the platelets seemed to be normal in all respects. Lelong and Soulier (1950) again confirmed the 
functional normality of the platelets in six cases, and found that the prothrombin consumption test gave normal results, as was confirmed by Cazal and Izarn (1950). The same clinical picture and haematological results have been recorded by O'Brien (1951), reporting a family of 38 members of whom six females and seven males were affected. This author, pointing out that in both hereditary haemorrhagic telangiectasia and von Willebrand's disease the same capillary defect exists, and that the two diseases are inherited in a similar way and may occur in the same family, has suggested the name diffuse capillary telangiectasia for the condition.

From the mass of literature available the clinical picture of von Willebrand's disease becomes clear. The tendency to bleed appears most often in childhood and takes the form of recurrent epistaxis, bruising, bleeding following dental operations, gastro-intestinal bleeding, prolonged bleeding from injury and from operation sites. Menorrhagia and post-partum haemorrhage may be severe in women. Haemarthrosis has been reported, and, rarely, haemorrhage into deep tissues and organs. The sexes are equally affected and the family history in the vast majority of families shows the inheritance of the condition to be of the simple dominant type, though some authors have reported families where sex-linkage appears to be present. The disease appears to be cyclic in character, and to decrease in severity with increasing age.

While doubts as to the clinical picture are never marked, the haematological findings are more confused, mainly due, perhaps, to the difficulties of retrospective assessment of findings where such variations in the normal are accepted and where, therefore, different authorities may disagree on the true diagnosis of certain families in whom divergencies from the accepted pattern occur. It is agreed that the findings in von Willebrand's disease are a prolonged bleeding time, a normal platelet count, and a normal coagulation time. There appears to be no functional abnormality of the platelets. The majority of investigators state that prothrombin times and the results of the prothrombin consumption test are normal. Clot retraction is reported as normal in the great majority of cases, Biggs and Macfarlane in their review of the literature giving a figure of 69 of 73 investigations. Capillary morphology and function have been reported as abnormal by several authors, suggesting that the dyscrasia is the result of this abnormality rather than a defect in the coagulation system.

This paper records a further family of 64 members, extending over five generations, of whom 21 are, or were, affected. A total of 33 members have been examined and investigated, and in 11 affected members the haemorrhagic diathesis has been the subject of a full investigation using current technical methods.

\section{Material and Methods}

Interest in the family arose with the examination of one member (IV, 23) attending the hospital as an out-patient with a history highly suggestive of von Willebrand's disease. From this case 64 members of her family have been traced and the history of 33 of them has been taken personally, including 18 of the 21 affected members. In the remaining 31 members the history has been checked from three independent sources before being accepted. Only three affected members have been so assessed, two being dead (I, 1 and II, 5) and one being unavailable for personal investigation (II, 6). The 33 members seen personally were fully examined clinically. In the 18 affected members so examined no organic cause for the bleeding from any individual site was found.

The bleeding and clotting times have been done on at least two occasions on the 15 members seen in whom no history of abnormal bleeding exists. In every case on each occasion the results lay welb within the normal limits. The remaining 18 mem $^{\circ}$ bers seen by us have all been affected: in seven of them the bleeding and clotting times have been estimated on several occasions while in the remaining 11 , in addition to estimating bleeding and clotting times on several occasions, a full investigation has been made, in seven on two occasions. This has included the following tests:-

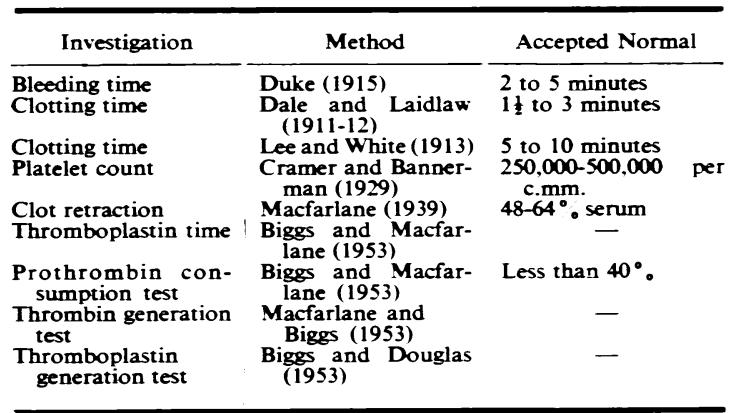

With the exceptions of the methods used for the bleeding time and the platelet count, these being standard in this hospital for many years, all the techniques used are those recommended by Biggs and Macfarlane, and great care has been taken to assure a standard technique. The fibrinogen content of the plasma has been estimated crudely by the addition of thrombin solution under standard 


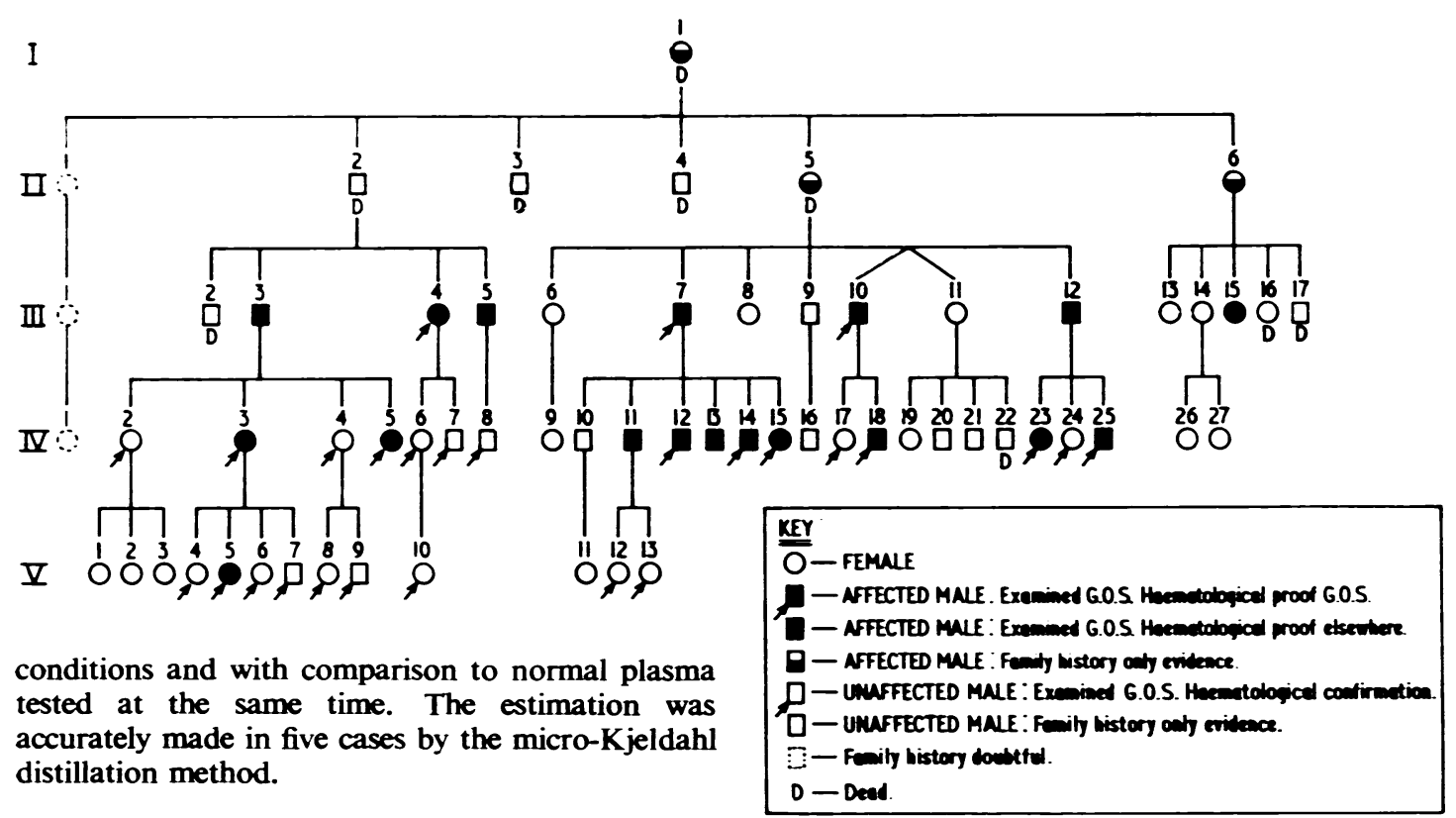

Results

Fig. 1 shows the family tree. Of the total of 64 , 38 are female of whom 10 are, or were, affected (two being dead), and 26 are male of whom 11 are affected. The seeming preponderance of males affected is well within the bounds of chance distribution and both sexes in this family are therefore equally affected. From Fig. 1 the disease appears to be inherited as a simple dominant, for there is only the evidence of his family that Case II, 2 was not affected though three of his four children had the condition transmitted to them. In view of the fact that the dyscrasia may be so mild in character in any one person, hearsay evidence, no matter how substantial, must be regarded as inconclusive. This point was borne out in Case III, 10. Two of his brothers, themselves affected, affirmed that he was unaffected, yet at a personal interview later he gave a history of recurrent epistaxis and haemorrhage following dental extractions, 'though nothing like as bad as my brothers', and his bleeding time on two occasions was found to be 10 minutes and in excess of 20 minutes.

Of the 21 affected members there is haematological confirmation in 18 , two being dead and one unavailable for investigation and never investigated elsewhere, though there is no doubt clinically that she is moderately affected. The age of onset of the symptoms has been variable: nine members were 5 years of age or less when the disease first became manifest, four were between 6 and 10 years, two were in their 'teens, two showed the first evidence at

21 and 23 years respectively, in two (both dead) the age of onset is unknown, while in the remaining two, in whom abnormal bruising is the only symptom, the onset is difficult to determine but was certainly at a very early age. Of the 43 unaffected members 16 are still under 10 years of age.

The pattern of the bleeding is remarkably uniform and conforms in every way to the classical picture. Of the 21 affected members, 16 have recurrent epistaxis as the main symptom; 11 suffer from prolonged and uncontrollable bleeding following some dental extractions; seven bruise abnormally easily; three have had recurring gastro-intestinal haemorrhages, of whom two have the proven concomitant of peptic ulceration and the third has a clinical history highly suggestive of such without actual confirmation. Of the seven affected females who have passed the menarche only one complains of menorrhagia and that is doubtful, while five of them have experienced no bleeding complication at parturition in a total of 24 births. One member $(\mathrm{V}, 5)$ at 5 years is at the moment free of all symptoms, though on two occasions the bleeding time has been in excess of 10 minutes. In this family there has been no case of haemarthrosis, haematuria, or haemorrhage into any cavity or organ. Nor does any affected member suffer from excessive bleeding from cuts or injuries.

The severity of the bleeding varies considerably in the 21 affected members, from the as yet symptom- 
less Case V, 5 to the severely disabled Cases III, 5 and III, 7. The last in his boyhood and adolescence was absent from school for more than half each year through recurrent epistaxis, each attack of which lasted for several days and completely debilitated him for two or three weeks at a time. For the same reason he was unable to hold any stable occupation until the age of 24 , his epistaxis being complicated by then by frequent haematemeses and intestinal haemorrhages sufficiently severe to require numerous, and at times quite massive, transfusions. Though the attacks of epistaxis have become less frequent and severe with the years the intestinal haemorrhages have remained, and only in his midthirties was there proof of concomitant duodenal ulceration. Even now these haemorrhages absent him from work at least twice yearly, and as yet no surgeon has suggested operation for his relief though his history following dental extractions and the records of his bleeding times make it quite clear that he has periods of remission when presumably operation could be undertaken.

Ten of the 21 affected members are affected to a degree which causes but transient embarrassment, while in six more the bleeding requires only short bed rest. Of the remainder, three have bleeding sufficiently severe to necessitate prolonged rest on occasion, while the only two who have required transfusion have already been referred to. In both transfusion has followed intestinal haemorrhage, and Case III, 5 has a history highly suggestive of peptic ulceration though there is no proof.

Bleeding from the nose is in the vast majority the only symptom causing embarrassment, in most being transient but in Case IV, 23 extremely severe. Her parents state that when very young she stopped bleeding only when she 'had bled herself out', and we ourselves have witnessed a fall of haemoglobin from $13.7 \mathrm{~g}$. to $8 \cdot 1 \mathrm{~g}$. per $100 \mathrm{ml}$. in a period of two days. Her attacks fortunately are becoming less frequent; even now at the age of 10 , whereas from 4 to 8 years of age they necessitated long absences from school on several occasions each year, they now occur roughly twice each year and are much less severe.

The mechanism of the epistaxis is undoubtedly not due to any abnormal venous plexus of the nasal mucosa. Quite apart from the completely negative physical findings in the recorded cases and in this family, the father and uncle of Case IV, 23 (Cases III, 12 and III, 10) were both amateur boxers while in the Royal Navy, the father very much so. No amount of physical trauma caused nasal bleeding, yet within a few days of a fight their dyscrasia could produce considerable haemorrhage, originally lasting several days in the case of the father.
The character of the bleeding in every case old enough for an individual pattern to have become established is quite definitely periodic but little more than that. Those members suffering from epistaxis have no precipitating factor, while the periods of both bleeding and freedom therefrom are entirely personal and completely unpredictable, varying from a few days of scanty bleeding separated by many months of freedom to severe bleeding extending over several weeks with but short remissions and relatively short periods of freedom. The pattern in any one case, however, is uniform: if severe at the onset, or soon after, the affliction remains severe. There is a definite tendency for the attacks to become less severe and less frequent with advancing years in most of the moderately or severely affected members. In the case of bleeding following dental extractions the periodicity of the condition is most marked. All the affected adults have on occasion had bleeding which has remained uncontrolled for several hours or even several days, while on other occasions no haemorrhage has occurred. Four of the adults, while in the Armed Services and where their condition was well known, state quite definitely that at the latter extractions there has been no prolongation of the bleeding time, while at others $\sigma$ followed by bleeding the bleeding time has been 0 found to be prolonged. We know that this is so ing three other members of the family. The possibility of surgical interference without post-operative haemorrhage is also made clear in this family by the fact that five affected members have had uncomplicated abdominal operations, one of them on three occasions, while a sixth had her tonsils and adenoids removed without post-operative bleeding. There exists in this family no relationship between sex and incidence, severity, age of onset, or site of bleeding.

From all the laboratory investigations the only abnormal finding has been prolonged bleeding time, varying from 7 minutes 30 seconds to several hours and bearing no relationship to the severity of the disease in any one case. In 12 of the 18 cases in which laboratory data are available the bleeding time has been found to be normal on occasions and prolonged on others, and this fluctuation has been observed personally in four cases. Of the remaining six cases, in three the time has been prolonged on every occasion of examination and in the other three prolonged on the one occasion on which the test was done.

In the 11 cases investigated thoroughly all the other findings have been normal, in four on the one occasion on which the full investigation was made and in the other seven on both occasions when 
the blood was so examined. The clot retraction on every occasion was normal, there was no defect of the blood coagulation factors, and no abnormality of the number, morphology or function of the platelets. The thrombin generation, thromboplastin generation, and prothrombin consumption tests were all normal. There was no quantitative or qualitative defect of fibrinogen and the thromboplastin time was also normal. The nail-bed capillaries have been studied in these 11 cases, and in the seven other affected members seen by us. Probably through initial inexperience we have not observed any gross abnormality in the shape of the capillaries not also encountered in the normals examined, but in two cases studied later in the series dilatation of some loops has been observed and in these two the capillaries have failed to retract on puncture. Such evidence as this provides does confirm the finding originally reported by Macfarlane and later confirmed by Perkins (1946), Levy (1947), and O'Brien (1951).

\section{Conclusions}

The study of this family confirms the established clinical picture of von Willebrand's disease recorded in the numerous reports of similar families contained in the literature. The disease consists of a tendency to bleed, the tendency being cyclic and decreasing with age. The disease becomes manifest usually at an early age, both sexes are equally affected, and the dyscrasia is inherited as a simple Mendelian dominant.

The danger in surgical operations is obvious, but that such may be performed without untoward complication is theoretically possible in view of the periodic nature of the disease, and in the practical sphere by the almost universal statement of patients that they bleed following some dental extractions and not following others. Though the danger in emergency operations remains, it does appear that surgical interference is possible without capillary haemorrhage whenever the bleeding time of the individual patient is within normal limits and that operations should await such a finding.

Laboratory investigation of the bleeding diathesis shows the only abnormality to be a prolonged bleeding time when the patient is in a bleeding phase'. The clotting time is invariably normal, the platelets normal in number and in morphology. Most investigators report that clot retraction is efficient and that prothrombin time and consumption are within normal limits. These findings have all been confirmed by a study of this family and in the 11 cases fully investigated the thrombin and thromboplastin generation tests have also shown the function of the platelets to be normal. A study of the nailbed capillaries has, in two members of the family, shown the defect of retraction first noted by Macfarlane.

The literature of von Willebrand's disease is reviewed.

A family of 64 members, extending over five generations, and containing 21 affected members, is recorded. The symptoms are detailed and clinical examination of the family confirms the accepted pattern of the disease and reveals no organic cause for the bleeding from any one site.

Full haematological examination of 11 affected members reveals no abnormality of function of the platelets and confirms that the only pathological finding is a prolongation of the bleeding time during a bleeding phase.

It is suggested that surgical interference should be possible during those phases when the bleeding time of an affected member is normal.

We are indebted to Mr. G. W. Cecil for much technical assistance throughout the investigation.

\section{Addendum}

Since the acceptance of this article for publication, Case III, 7 has been successfully operated on for his chronic duodenal ulcer. Operation was postponed until his bleeding time was normal and he was operated on by Mr. J. L. Stephen, consultant surgeon, Paddington General Hospital, London. The operation was a routine ante-colic PolyaHofmeister gastrectomy. No precautions were taken against haemorrhage apart from meticulous haemostasis of all cut surfaces. The patient's bleeding time remained normal for five days after operation and there were no complications.

\section{REFERENCES}

Biggs, R. and Douglas, A. S. (1953). J. clin. Path., 6, 23.

and Macfarlane, R. G. (1953). Human Blood Coagulation and its Disorders. Oxford.

Cazal, P. and Izarn, P. (1950). Acta haemat.. Basel, 6, 357

Cramer W and Bannerman, R. G. (1929). Lancet, 1, 992.

Dale, H. H. and Laidlaw, P. P. (1911-12). J. Path. Bact., 16, 351.

Duke, W. W. (1915). J. Amer. med. Ass., 65, 1600.

Estren, S., Sanchez Médal, L. and Dameshek, W. (1946). Blood. 1, 504 .

Glanzmann, E. (1918). Jb. Kinderheilk., 88, 113

Jürgens, R. and Naumann, W. (1931). Disch. Arch. klin. Med. 172. 248.

Lee, R. I and White, P. D. (1913). Amer. J. med. Sci., 145, 495

Lelong M. and Soulier, J. P. (1950). Rev. Hémat., 5. 13.

Levy, L. (1947). Ann. intern. Med., 27, 96.

Macfarlane, R. G. (1939). Lancet, 1, 1199. (1941). Quart. J. Med., n.s. 10, 1

- and Biggs, R. (1953). J. clin. Path., 6, 3.

OBrien. J. R. (1951). Proceedings of the Third International Congress of the International Society of Hematology, Cambridge. England 1950, 546 Grune \& Stratton, New York. bridge, England, 1950, p. 546

Revol, L., Favre-Gilly, J. and Ollagnier, C. (1950). Rev. Hémat.. 5., 24 .

Willebrand. E. A. von (1926). Finska LäkSällsk. Handl., 68. 87. (1931). Acta med. scand. 76, 521

Jürgens, R. (1933). Dtsch. Arch. klin. Med., 175, 453. 